www.jmscr.igmpublication.org

Impact Factor 5.84

Index Copernicus Value: 71.58

ISSN (e)-2347-176x ISSN (p) 2455-0450

crossref DOI:_https://dx.doi.org/10.18535/jmscr/v5i11.131

Journal Of Medical Science And Clinical Research

\title{
A Comparative Study of Prevalence of Depression and Associated Risk Factors among the Elderly Population
}

\author{
Author \\ Manoj Kumar \\ Professor and HOD, Department of Community Medicine, Venkateshawara Institute of Medical Sciences, \\ Gajraula, Amroha, U.P., India
}

\begin{abstract}
Introduction: Depression (major depressive disorder) is a common and serious medical illness that negatively affects how you feel, the way you think and how you act. Depression is now categorised among the most common psychiatric disorders among the elderly people. It is projected that by 2050, elderly will constitute 20-30\% of India's population. the median prevalence rate of depressive disorders in the world for the elderly population was determined to be $10.3 \%$, while among the elderly Indian population, it was determined to be $21.9 \%$.

Aim: This study aimed to estimate the prevalence of depression in the elderly population ( $>60$ years old) Material and Method: It is a cross sectional study, with a total sample size of 1060 elderly persons. For assessment of depression a 15-item geriatric depression scale (GDS) which consists of 15 self-report items was used in the study

Results: It was observed that majority of the subjects included in study had Mild depression (38.6\%) and least (4.05\%) of the elderly were severely depressed. Male and Female population in this study were almost equally distributed with male population (40.5\%) being affected more by depression then the female population (39.6\%) and Majority of subjects in the study were married (59.6\%), and lived in a joint set up of family (81.6\%). Majority of them were literate (67.9\%) and financially not independent. Only the association between type of family, education and financial dependency with depression was found to be statically significant $(p=0.00)$ and rest variables were found to be statistically nonsignificant

Conclusion: With increasing longevity and proportion of the elderly population in India, Depression in elderly is a significant problem. As the trend now a days is towards urbanization and nucleation of the families, this problem may be categorised as "public health problem" in the near future.
\end{abstract}

\section{Introduction}

Depression (major depressive disorder) is a common and serious medical illness that negatively affects how you feel, the way you think and how you act. Depression can results in reduced life satisfaction and quality and along with that it also leads to cognitive decline as well as impairments in activities of daily living. The Global Burden of Disease (GBD) study projections show that depression will be the single leading cause of Disability Adjusted Life Years by 2020 in the developing world. ${ }^{1,2}$ Depression is now categorised among the most common psychiatric disorders among the elderly people., 
As Ageing is a process during which a gradual transition takes place both physically and mentally. It is projected that by 2050 , elderly will constitute $20-30 \%$ of India's population. ${ }^{2}$ In reports of community -based mental health surveys on geriatric depressive disorders in those aged 60 years and above, conducted in the continents of Asia, Europe, Australia, North America, and South America between 1955 and 2005, the median prevalence rate of depressive disorders in the world for the elderly population was determined to be $10.3 \%$, while among the elderly Indian population, it was determined to be $21.9 \%$. $^{5}$

Few community-based studies have been conducted in India so far to address this issue. Still Limited studies are there in literature to assess relation of depression among the elderly population and its causative variables. Hence, this study was conducted to estimate the prevalence of depression in the elderly ( $>60$ years old)

\section{Material and Methods}

It is a cross sectional study, conducted in Department of Community Medicine for a period of 1 year and 4 months. A total sample size of 1060 elderly persons were included in this study. Approval of the Institutional Ethics Committee was obtained prior to commencement of the study. All the subjects of the study were interviewed using pre-designed, pre-tested and semi-structured questionnaire containing various socio-demographic parameters after obtaining their prior consent. Exclusion criteria: The deaf/dumb/blind, those with diagnosed psychiatric illness (schizophrenia, mental retardation) or neurological disorders (Parkinsonism, severe head injury, or brain neoplasm), and those who were ill at the time of the study were excluded, as there was no way to obtain reliable information from them.

For assessment of depression a 15-item geriatric depression scale (GDS) which consists of 15 selfreport items was used in the study. ${ }^{6}$ Accuracy of the GDS-15 is not affected due medical conditions, age, or other bio-social characteristics.
Even presence of a major depressive episode among elderly home-bound adults can be reliably assessed. Those with a GDS score > 5 were categorized as depressed.

\section{Statistical analysis}

All the obtained Data was tabulated and evaluated and then statistical analysed Frequency distributions were calculated for almost all the variables. To test significant associations between independent variables and depression, chi-square test was used ( $\mathrm{p}<0.05)$.

\section{Results}

Out of total 1060 study subjects present in the study, on the basis of GDS-15 scores it was observed that majority of the subjects included in study had Mild depression (38.6\%) and least $(4.05 \%)$ of the elderly were severely depressed.

The age group included in the study ranged from above 60 yrs to above 80 yrs. These were sub categorized, out of which $60 \%$ were aged from 60-70 years followed by $31.9 \%$ in age range of $70-80$ yrs and just $8 \%$ above $80 \mathrm{yrs}$ of age.

Male and Female population in this study were almost equally distributed with male population $(40.5 \%)$ being affected more by depression then the female population (39.6\%) and Majority of subjects in the study were married (59.6\%), and lived in a joint set up of family $(81.6 \%)$

The study subjects belonged to almost equally distributed socioeconomic status. Majority of them were literate $(67.9 \%)$ and financially not independent. (Table 1)

It was observed that only the association between type of family, education and financial dependency with depression was found to be statically significant $(p=0.00)$ and rest variables were found to be statistically non-significant. 
Table 1: Showing Relationship between Socio-Demographic Variables and Depression $(\mathrm{N}=1060)$.

\begin{tabular}{|l|c|c|c|c|}
\hline Variables & & With Depression & Without Depression & Total \\
\hline AGE & $60-70$ & $346(38.6)$ & $390(61.3)$ & $636(60 \%)$ \\
& $70-80$ & $134(39.5)$ & $205(60.4)$ & $339(31.9)$ \\
\hline Gender & Above 80 & $39(45.8)$ & $46(54.1)$ & $85(8 \%)$ \\
\hline Type & Male & $214(40.5)$ & $314(59.4)$ & $528(49.8)$ \\
Family & Female & $211(39.6)$ & $321(60.33)$ & $532(50.1)$ \\
\hline Marital Status & Nuclear & $93(47.6)$ & $102(52.3)$ & $195(18.3)$ \\
& Joint & $380(43.9)$ & $485(56.1)$ & $865(81.6)$ \\
\hline Socioeconmic & Married & $245(38.7)$ & $387(61.2)$ & $632(59.6)$ \\
Status & Unmarried & $51(53.1)$ & $45(46.8)$ & $96(9.05)$ \\
& Others & $173(52.1)$ & $159(47.8)$ & $332(31.3)$ \\
\hline Education & Middle And Above & $228(42.3)$ & $311(57.6)$ & $539(50.8)$ \\
& & & & \\
& Lower Middle And Below & $198(38)$ & $323(61.9)$ & $521(49.1)$ \\
\hline Employment & Illiterate & $198(58.23)$ & $142(42.05)$ & $340(32.07)$ \\
& Literate & $231(32.08)$ & $489(67.9)$ & $720(67.9)$ \\
\hline
\end{tabular}

\section{Discussion}

The prevalence of depression, based on GDS scores $>5$, was found to be $6.05 \%$ in the present study. These results were comparatively less as compared to the other similar studies done in different areas like Ludhiana, Bihar, Vellore and Dharwad by various authors. ${ }^{7,8,9}$ This difference may be attributed due to different characteristics of the study population and difference in number of the total sample taken for the study.

In this study though male and female population were almost equally distributed still males were more associated with depression in comparision to females, though this difference was not statistically significant. This was in contrary with study report of Sengupta $\mathrm{P}^{7}$ and some other authors $^{10,11}$, in which they reported more statistically significant female preponderance. However no such findings were observed by Kumar et $\mathrm{al}^{12}$ and Goyal et $\mathrm{al}^{13}$.

In the present study marital status was not significantly related to depression which was in accordance with the results of authors like Sengupta $\mathrm{P}^{7}$ and Goyal $\mathrm{A}^{13}$ where as Sinha et al 10 and Taqui et $\mathrm{al}^{14}$ reported an association of those who were single (divorced, separated, widow, unmarried) with depression.
Depression was found significantly higher among those who belonged to upper socioeconomic group and those who were not financially dependent on other.

A significant association was observed between education and financial status with depression which was in accordance with Pracheth $\mathrm{R}^{8}$ and Jain $\mathrm{RK}^{11}$.

Taking a review of some other studies it was observed that in one study done in Pakistan female gender, elderly without a spouse, low level of education, and unemployment were found to be independent predictors of dipression. ${ }^{14}$ Similar findings have been reported among the geriatric population in the urban slums of Mumbai and Dharwad. ${ }^{15}$

However, a study on in Tamil Nadu found that age, female gender, cognitive impairment, and disability status were not significantly associated with geriatric depression. ${ }^{12}$

\section{Conclusion}

With increasing longevity and proportion of the elderly population in India, Depression in elderly is a significant problem. As the trend now a days is towards urbanization and nucleation of the families, this problem may be categorised as "public health problem" in the near future. 


\section{References}

1. Murray CJ, Lopez AD. Alternative projections of mortality and disability by cause 1990-2020: Global Burden of Disease Study. Lancet 1997;349:1498504.

2. United Nations Dept. of International Economic and Social Affairs, population Division (2010) World Population Ageing 2009, United Nations NY. 2010

3. Radhakrishnan S, Nayeem A. Prevalence of depression among geriatric population in a rural area in Tamilnadu. Int $J$ Nutr Pharmacol Neurol Dis. 2013;3:309-12.

4. Satcher D. Mental Health: A report of the surgeon general executive summary. Prof Psychol Res Pr. 2000;31:5-13.

5. Barua A, Ghosh MK, Kar N, Basilio MA. Depressive disorders in Elderly: An estimation of this public health problem. J Int Med Sci Acad 2011;24:193-4.

6. Ganguly M, Dubey S, Johnston JM, Pandav R, Chandra V, Dodge HH. Depressive symptoms, cognitive impairment and functional impairment in a rural elderly population in India: A Hindi version of the Geriatric Depression Scale (GDS-H). Int J Geriatr Psychiatry. 1999;14:807-20.

7. Sengupta P, Benjamin AI. Prevalence of depression and associated risk factors among the elderly in urban and rural fi eld practice areas of a tertiary care institution in Ludhiana. Indian $\mathrm{J}$ Public Health. 2015;59:3-8.

8. Pracheth R, Mayur SS, Chowti JV. Geriatric Depression Scale: A tool to assess depression in elderly. Int J Med Sci Public Health. 2013;2:31-5.

9. Soni S, Shukla M, Kumar M. Prevalence of depression and associated risk factors among the elderly in rural field practice areas of a tertiary care institution in Katihar, Bihar. Int J Adv Med 2016;3:1016-9.
10. Sinha SP, Shrivastava SR, Ramasamy J. Depression in an Older Adult Rural Population in India. MEDICC Review. 2013;15(4):41-4.

11. Jain RK, Aras RY. Depression in geriatric population in urban slums of Mumbai. Indian J Public Health. 2007;51:112-3.

12. Rajkumar AP, Thangadurai P, Senthilkumar P, Gayathri K, Prince M, Jacob KS. Nature, prevalence and factors associated with depression among the elderly in a rural south Indian community. Int Psychogeriatr. 2009;21:372-8.

13. Goyal A, Kajal KS. Prevalence of Depression in Elderly Population in the Southern Part of Punjab. Family Med Prim Care. 2014;3(4):359-61.

14. Taqui AM, Itrat A, Qidwai W, Qadri Z. Depression in the elderly: Does family system play a role? A cross-sectional study. BMC Psychiatry. 2007;7:57.

15. Kamble SV, Dhumale GB, Goyal RC, Phalke DB, Ghodke YD. Depression among elderly persons in a Primary Health Centre area in Ahmednagar, Maharastra. Indian J Public Health 2009;53:253-5. 